\title{
Frondihabitans peucedani sp. nov., an actinobacterium isolated from rhizosphere soil, and emended description of the genus Frondihabitans Greene et al. 2009
}

\author{
Soon Dong Lee
}

Correspondence

Soon Dong Lee

sdlee@cheju.ac.kr or

sdlee@jejunu.ac.kr

\author{
Department of Science Education, Jeju National University, Jeju 690-756, Republic of Korea
}

The genus Frondihabitans was recently established in the family Microbacteriaceae by Greene et al. (2009) to replace the illegitimate name 'Frondicola' (Zhang et al., 2007). The type strain of the only known species, Frondihabitans australicus, was isolated from decaying leaf litter of a pine forest. Members of the genus Frondihabitans possess a type B2 $\beta$ peptidoglycan with ornithine as the diagnostic diamino acid, fatty acids $\mathrm{C}_{18: 1} \omega 7 c$ and $\mathrm{C}_{14: 0} 2-\mathrm{OH}$, menaquinones MK-8 and MK-7 and polar lipid profiles that include several unknown glycolipids. The genus is phylogenetically related to the genus Frigoribacterium of the family Microbacteriaceae. In this paper, I describe the isolation and classification of a Frondihabitans strain from rhizosphere soil of a plant (Peucedanum japonicum Thunb.).

During a culture-dependent study on rhizosphere bacteria, strain RS- $15^{\mathrm{T}}$ was isolated from rhizosphere soil of a cliffassociated plant (Peucedanum japonicum Thunb.) on Mara

The GenBank/EMBL/DDBJ accession number for the 16S rRNA gene sequence of strain RS-15 $5^{\top}$ is FM998017.

A comparison of fatty acid profiles is available as supplementary material with the online version of this paper.
Island, Jeju, Republic of Korea. The procedure and medium for bacterial isolation were described previously (Lee, 2009). The isolate was maintained on International Streptomyces Project (ISP) 2 medium (Shirling \& Gottlieb, $1966)$ and as $20 \%(\mathrm{v} / \mathrm{v})$ glycerol suspensions at -20 and $-80{ }^{\circ} \mathrm{C}$. For phenotypic comparison and DNA-DNA hybridization, Frondihabitans australicus DSM $17894^{\mathrm{T}}$ was grown on trypticase soy agar (TSA; Difco).

Cell morphology and motility were observed by using phase-contrast and transmission electron microscopy. Colony morphology and pigmentation were observed with cells grown on ISP 2 for 3 days at $30{ }^{\circ} \mathrm{C}$. Growth was examined on ISP 2 at $4-42{ }^{\circ} \mathrm{C}$ and at $\mathrm{pH} 4.1-12.1$, at intervals of $1 \mathrm{pH}$ unit, adjusted with $6 \mathrm{M} \mathrm{HCl}$ or $10 \mathrm{M}$ $\mathrm{NaOH}$ before sterilization. $\mathrm{NaCl}$ tolerance for growth was tested on ISP 2 with $1-9 \%(\mathrm{w} / \mathrm{v}) \mathrm{NaCl}$, at intervals of $1 \%$. Gram staining and catalase and oxidase activities were tested as described previously (Lee, 2007). Decomposition of hypoxanthine, DL-tyrosine and xanthine was tested according to the method of Gordon et al. (1974). Hydrolysis of casein and cellulose was determined on ISP 2 medium amended with $1 \%(\mathrm{w} / \mathrm{v})$ skimmed milk and $0.5 \%(\mathrm{w} / \mathrm{v})$ cellulose, respectively. Hydrolysis of starch and 
DNA was determined by using starch agar (Difco) and DNase test agar (Difco), respectively. Utilization of substrates was tested using GN2 MicroPlates (Biolog) for 95 substrates, inoculated with cells of strain RS- $15^{\mathrm{T}}$ grown on ISP 2 for 3 days at $30{ }^{\circ} \mathrm{C}$ and suspended in sterilized distilled water, following the manufacturer's instructions, and incubated for $48 \mathrm{~h}$ at $30{ }^{\circ} \mathrm{C}$. Other physiological and biochemical properties were determined using API 20NE and API ZYM strips (bioMérieux), following the instructions of the manufacturer.

Strain RS- $15^{\mathrm{T}}$ grew well on ISP 2, TSA and nutrient agar (Difco), with extensive production of extracellular polysaccharides on ISP 2. Cells of strain RS- $15^{\mathrm{T}}$ were Gramstain-positive, aerobic, non-motile, irregular, short rods $(0.3-0.5 \times 0.9-1.0 \mu \mathrm{m})$. Colonies were circular, smooth, convex and bright yellow with entire margins after incubation on ISP 2 for 3 days at $30{ }^{\circ} \mathrm{C}$. The results for other physiological and biochemical properties are given in Table 1 and the species description.

Table 1. Differential characteristics between strain RS $-15^{\top}$ and Frondihabitans australicus $\mathrm{E} 1 \mathrm{HC}-02^{\top}$

Strains: 1, Frondihabitans peucedani sp. nov. RS- $15^{\mathrm{T}} ; 2$, Frondihabitans australicus E1HC- $02^{\mathrm{T}}$ (unless indicated, data from Zhang et al., 2007). + , Positive; w, weak; -, negative.

\begin{tabular}{|c|c|c|}
\hline Characteristic & 1 & 2 \\
\hline Cell size $(\mu \mathrm{m})$ & $0.9-1.0 \times 0.3-0.5$ & $0.5-1.0 \times 0.2-0.4$ \\
\hline \multicolumn{3}{|l|}{ Temperature for growth $\left({ }^{\circ} \mathrm{C}\right)$} \\
\hline Range & $4-37$ & $15-37$ \\
\hline Optimum & $20-30$ & 30 \\
\hline \multicolumn{3}{|l|}{$\mathrm{pH}$ for growth } \\
\hline Range & $5.1-12.1$ & $6.0-9.5$ \\
\hline Optimum & $8.1-11.1$ & 9.1 \\
\hline \multicolumn{3}{|l|}{ Enzyme activities (API ZYM) ${ }^{\star}$} \\
\hline Acid phosphatase & + & w \\
\hline Esterase (C4) & - & $\mathrm{W}$ \\
\hline$\alpha$-Galactosidase & - & + \\
\hline$\beta$-Glucosidase & $\mathrm{W}$ & + \\
\hline$N$-Acetyl- $\beta$-glucosaminidase & + & - \\
\hline$\alpha$-Mannosidase & - & + \\
\hline $\begin{array}{l}\text { Naphthol-AS-BI- } \\
\text { phosphohydrolase }\end{array}$ & + & - \\
\hline Cystine arylamidase & - & $\mathrm{W}$ \\
\hline Valine arylamidase & - & + \\
\hline \multicolumn{3}{|l|}{ Assimilation of (API 20NE):* } \\
\hline D-Glucose & - & + \\
\hline D-Mannose & - & + \\
\hline D-Mannitol & - & + \\
\hline $\mathrm{N}$-Acetyl-D-glucosamine & - & + \\
\hline Polar lipids $\dagger$ & PG, PL, GL, L & DPG, PG, PL, GL \\
\hline DNA G $+C$ content $(\mathrm{mol} \%)$ & 68.3 & $71 \pm 1$ \\
\hline
\end{tabular}

${ }^{\star}$ Data obtained in this study with strain DSM $17894^{\mathrm{T}}$.

$\nmid$ DPG, Diphosphatidylglycerol; PG, phosphatidylglycerol; GL, unknown glycolipids; PL, unknown phospholipids; L, unknown lipids.
Extraction of genomic DNA and amplification of the $16 \mathrm{~S}$ rRNA gene by PCR were performed as described by Lee (2007). The resultant PCR product was purified and sequenced directly using an automatic DNA sequencer (model 3730xl) with a BigDye Terminator cycle sequencing kit (both from Applied Biosystems). The CLUSTAL X program (Thompson et al., 1997) was used for multiple alignment of the $16 \mathrm{~S}$ rRNA gene sequence of strain RS $-15^{\mathrm{T}}$ determined in this study and corresponding sequences retrieved from public databases. Phylogenetic analyses were performed using several programs of the PHYLIP software package (Felsenstein, 1993). A neighbour-joining tree (Saitou \& Nei, 1987) was constructed using an evolutionary distance matrix generated by the model of Jukes \& Cantor (1969). Bootstrap analysis (Felsenstein, 1985) was performed with 1000 neighbour-joining datasets.

A partial 16S rRNA gene sequence (1429 nt) of strain RS$15^{\mathrm{T}}$ was compared with those of members of the family Microbacteriaceae. In total, 1376 unambiguously aligned nucleotides were used for phylogenetic analyses. A $16 \mathrm{~S}$ rRNA gene sequence tree (Fig. 1) showed that strain RS$15^{\mathrm{T}}$ belongs to the family Microbacteriaceae and forms a tight phylogenetic cluster with Frondihabitans australicus E1HC-02 ${ }^{\mathrm{T}}$ (98.5\% $16 \mathrm{~S}$ rRNA gene sequence similarity). The relationship was supported by a high bootstrap value $(96 \%)$ and was also found in the trees constructed by the maximum-likelihood (Felsenstein, 1981) and maximumparsimony (Fitch, 1971) methods. Other closely related strains were Frigoribacterium faeni $801^{\mathrm{T}}(97.9 \%$ sequence similarity), Labedella gwakjiensis KSW2- $17^{\mathrm{T}}(96.8 \%)$ and Frigoribacterium mesophilum MSL- $08^{\mathrm{T}}$ (96.5\%). Strain RS$15^{\mathrm{T}}$ showed low levels of $16 \mathrm{~S}$ rRNA gene sequence similarity $(<95.7 \%)$ to other representatives of the family Microbacteriaceae.

To determine the amino acid composition of the peptidoglycan, purified cell walls were obtained as described by Hancock (1994). Hydrolysis of the purified cell walls was carried out by using $6 \mathrm{M} \mathrm{HCl}$ at $120^{\circ} \mathrm{C}$ for $16 \mathrm{~h}$. Quantitative analysis of amino acids in the purified peptidoglycan was performed by HPLC as described previously (Lee, 2007). The acyl type of the cell wall was analysed according to the method of Uchida \& Aida (1984). Menaquinones were analysed by HPLC as described by Kroppenstedt (1985). Analyses of polar lipids and mycolic acids were performed by TLC as described by Minnikin et al. (1975) and Minnikin et al. (1980), respectively. The $\mathrm{G}+\mathrm{C}$ content of the DNA was determined by HPLC (Mesbah et al., 1989). The DNA-DNA relatedness between strain RS- $15^{\mathrm{T}}$ and Frondihabitans australicus DSM $17894^{\mathrm{T}}$ was determined in duplicate by the initial renaturation method (De Ley et al., 1970; Huß et al., 1983), The cellular fatty acids of strain RS- $15^{\mathrm{T}}$ and Frondihabitans australicus DSM $17894^{\mathrm{T}}$ were determined by using cells grown on TSA for 3 days at $30{ }^{\circ} \mathrm{C}$. Methyl esters of cellular fatty acids were prepared and analysed according to the instructions of the Sherlock Microbial Identification System (version 6; MIDI). For assessing 


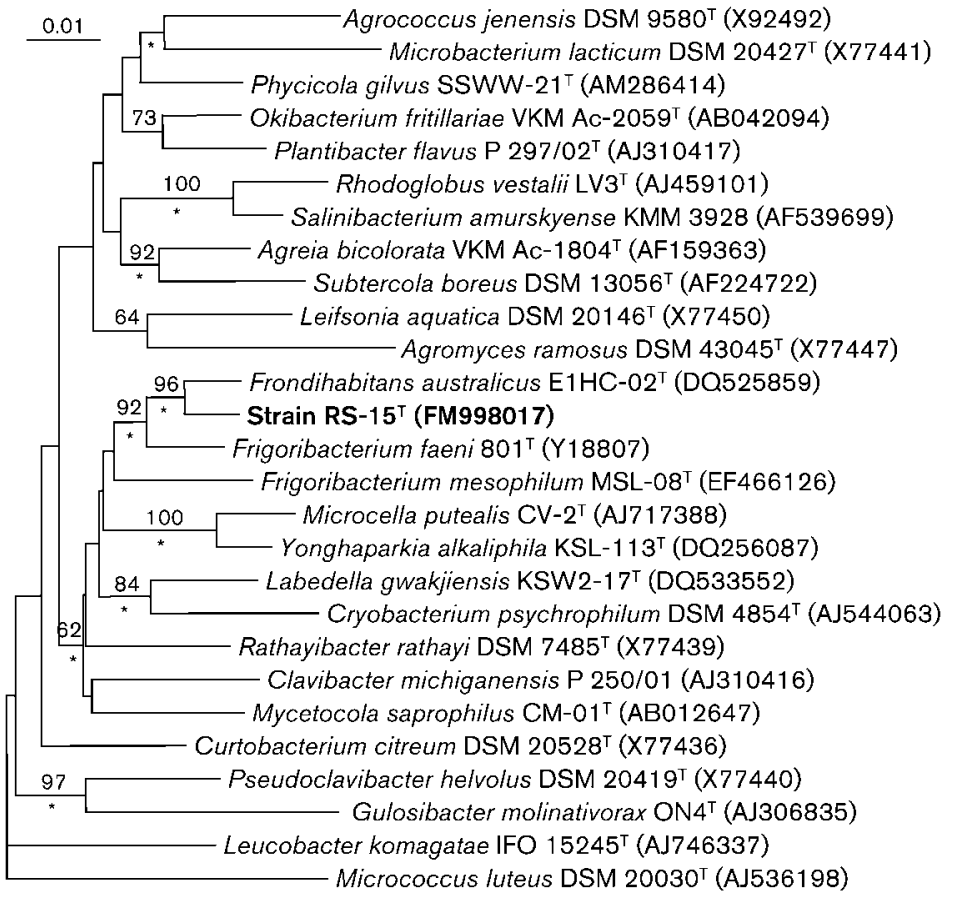

Fig. 1. Neighbour-joining tree showing the phylogenetic relationships between strain $\mathrm{RS}-15^{\mathrm{T}}$ and representatives of the family Microbacteriaceae based on 1376 unambiguously aligned nucleotides of the 16S rRNA gene. Bootstrap support values (>50\%) based on 1000 replications are shown at branch nodes. Asterisks indicate that the corresponding nodes were recovered in trees obtained by the maximum-likelihood and maximum-parsimony methods. Bar, 0.01 substitutions per nucleotide position. reproducibility, methyl esters of cellular fatty acids were analysed using two independent cultures obtained 30 days apart.

The cell-wall peptidoglycan of strain RS- $15^{\mathrm{T}}$ consisted of alanine, glutamic acid, ornithine, glycine and homoserine in the ratio $1.0: 1.0: 0.7: 3.0: 1.0$. Aspartate, serine and threonine were not detected in the cell wall. Based on these results, the structure of the linkage may be Orn-Ala, suggesting that strain RS-15 ${ }^{\mathrm{T}}$ possessed peptidoglycan of the type B2 $\beta$ [\{Gly\}[L-Hsr]D-Glu-D-Orn] (Schleifer \& Kandler, 1972). The murein was found to be $N$-acetylated. The menaquinones comprised MK-8, MK-9 and MK-7 in the ratio 75:15:10. Among these, MK-9 was reported to be absent from cells of Frondihabitans australicus DSM $17894^{\mathrm{T}}$ (Zhang et al., 2007). The polar lipids were phosphatidylglycerol, five unknown glycolipids, of which two were present as major components, three unknown phospholipids and two unknown lipids. Diphosphatidylglycerol, which was detected in cells of Frondihabitans australicus DSM $17894^{\mathrm{T}}$ (Zhang et al., 2007), was not found in the extract of strain RS- $15^{\mathrm{T}}$. Mycolic acids were absent. The cellular fatty acid profiles of strain RS-15 and Frondihabitans australicus DSM $17894^{\mathrm{T}}$ were reproducible in two independent experiments (Supplementary Table S1, available in IJSEM Online). The cellular fatty acid profile of strain RS-15 ${ }^{\mathrm{T}}$ was represented by considerable amounts of unsaturated, anteiso-methyl branched and 2hydroxy components. The predominant fatty acids were summed feature 7 (one or more of $\mathrm{C}_{18: 1} \omega 9 c, \mathrm{C}_{18: 1} \omega 12 t$ and $\left.\mathrm{C}_{18: 1} \omega 7 c ; 31.5-35.0 \%\right)$, anteiso- $\mathrm{C}_{15: 0}(28.4-30.9 \%)$ and $\mathrm{C}_{14: 0}$ 2-OH (16.7-18.7\%). On the other hand, Frondihabitans australicus DSM $17894^{\mathrm{T}}$ contained a large amount of $\mathrm{C}_{18: 1}(70.0-71.1 \%)$ together with moderate amounts of $\mathrm{C}_{14: 0} 2-\mathrm{OH}(6.5-9.7 \%)$, as also reported by
Zhang et al. (2007). The exact position of the double bond in the $\mathrm{C}_{18: 1}$ acid was not determined in this analysis. Strain RS$15^{\mathrm{T}}$ differed significantly from Frondihabitans australicus DSM $17894^{\mathrm{T}}$ in the type and relative amounts of major fatty acids, particularly anteiso- $\mathrm{C}_{15: 0}$ (Supplementary Table S1).

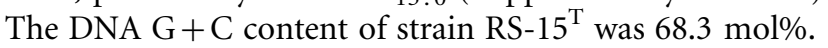

Duplicate DNA-DNA relatedness values between strain RS- $15^{\mathrm{T}}$ and Frondihabitans australicus DSM $17894^{\mathrm{T}}$ were 17.2 and $17.1 \%$, showing that strain RS- $15^{\mathrm{T}}$ belongs to a different species (Wayne et al., 1987). Strain RS-15 ${ }^{\mathrm{T}}$ is readily differentiated from Frondihabitans australicus DSM $17894^{\mathrm{T}}$ by phenotypic features such as temperature and $\mathrm{pH}$ ranges for growth, assimilation of carbon sources and enzyme activities (Table 1).

On the basis of the phenotypic and DNA-DNA hybridization data, strain $\mathrm{RS}-15^{\mathrm{T}}$ is considered to be a novel species of the genus Frondihabitans, for which the name Frondihabitans peucedani sp. nov. is proposed.

\section{Emended description of the genus Frondihabitans Greene et al. 2009}

The description of the genus Frondihabitans is as given by Zhang et al. (2007) and Greene et al. (2009) with the following amendments. Cells are aerobic, Gram-stainpositive, non-endospore-forming, non-motile, irregularshaped rods. Mesophilic. No mycelium is produced. A range of carbohydrates, organic compounds and amino acids are metabolized. The cell-wall peptidoglycan type is B2 $\beta$ with ornithine as the diagnostic diamino acid. The major menaquinone is $\mathrm{MK}-8$. The presence and relative amounts of MK-7 and MK-9 are variable according to the species. The predominant fatty acids are $\mathrm{C}_{18: 1}$ (with the 
exact position of the double bond being uncertain) and $\mathrm{C}_{14: 0} 2-\mathrm{OH}$ or $\mathrm{C}_{18: 1}$, anteiso- $\mathrm{C}_{15: 0}$ and $\mathrm{C}_{14: 0} 2-\mathrm{OH}$ depending on the species. The polar lipid profile comprises a common core of phosphatidylglycerol, glycolipids and unidentified phospholipids, with the presence of diphosphatidylglycerol being variable. The DNA G $+\mathrm{C}$ content is 68.3-71 mol\%.

\section{Description of Frondihabitans peucedani sp. nov.}

Frondihabitans peucedani [peu.ce.da'ni. L. n. peucedanum the plant hog's-fennel or sulphurwort and also a botanical genus name; L. gen. n. peucedani of Peucedanum, isolated from Peucedanum japonicum Thunb.].

Cells are Gram-stain-positive, aerobic, oxidase-negative, catalase-positive, non-motile, irregular, short rods (0.3$0.5 \times 0.9-1.0 \mu \mathrm{m})$. Colonies are circular, smooth and convex with entire margins and bright yellow after incubation on ISP 2 at $30{ }^{\circ} \mathrm{C}$ for 3 days. Grows at 4 $37{ }^{\circ} \mathrm{C}$ (optimum $20-30{ }^{\circ} \mathrm{C}$ ), at $\mathrm{pH}$ 5.1-12.1 (optimum $\mathrm{pH}$ 8.1-11.1) and with $4.0 \%(\mathrm{w} / \mathrm{v}) \mathrm{NaCl}$, but not with $5.0 \%$ (w/v) NaCl. Hydrolyses DNA, but not casein, cellulose or starch. Does not decompose hypoxanthine, DL-tyrosine or xanthine. $\mathrm{H}_{2} \mathrm{~S}$ production is not observed. Positive for aesculin degradation but negative for nitrate reduction, indole production, glucose fermentation, arginine dihydrolase, urease, gelatin hydrolysis and assimilation of (API 20NE) D-arabinose, potassium gluconate, $\mathrm{N}$-acetyl-Dglucosamine, D-glucose, maltose, D-mannose, D-mannitol, adipic acid, capric acid, DL-malic acid, trisodium citrate and phenylacetic acid. With API ZYM, positive for acid phosphatase, $\beta$-galactosidase, $\alpha$-glucosidase, $N$-acetyl- $\beta$ glucosaminidase, leucine arylamidase and naphthol-ASBI-phosphohydrolase, weakly positive for esterase lipase (C8) and $\beta$-glucosidase and negative for alkaline phosphatase, esterase (C4), lipase (C14), $\alpha$-chymotrypsin, $\alpha$-fucosidase, $\alpha$-galactosidase, $\beta$-glucuronidase, $\alpha$-mannosidase, trypsin, cystine arylamidase and valine arylamidase. With Biolog GN2, utilizes L-arabinose, D-arabitol, dextrin, D-fructose, Dgalactose, D-gluconic acid, lactulose, maltose, melibiose, Dpsicose, D-sorbitol and sucrose and, in contrast to the results obtained with API 20NE, $\alpha$-D-glucose, D-mannitol and Dmannose, but does not utilize $\alpha$-cyclodextrin, glycogen, Tweens 40 or $80, \mathrm{~N}$-acetyl-D-galactosamine, $\mathrm{N}$-acetyl-Dglucosamine, adonitol, cellobiose, i-erythritol, L-fucose, gentiobiose, myo-inositol, lactose, methyl $\beta$-D-glucoside, raffinose, L-rhamnose, trehalose, turanose, xylitol, methyl pyruvate, monomethyl succinate, acetic acid, cis-aconitic acid, citric acid, formic acid, D-galactonic acid lactone, Dgalacturonic acid, D-glucosaminic acid, D-glucuronic acid, $\alpha$-, $\beta$ or $\gamma$-hydroxybutyric acid, $p$-hydroxyphenylacetic acid, itaconic acid, $\alpha$-ketobutyric acid, $\alpha$-ketoglutaric acid, $\alpha$ ketovaleric acid, DL-lactic acid, malonic acid, propionic acid, quinic acid, D-saccharic acid, sebacic acid, succinic acid, bromosuccinic acid, succinamic acid, glucuronamide, L-alaninamide, D-alanine, L-alanine, L-alanyl glycine, Lasparagine, L-aspartic acid, L-glutamic acid, glycyl L-aspartic acid, glycyl L-glutamic acid, L-histidine, hydroxy L-proline, L-leucine, L-ornithine, L-phenylalanine, L-proline, L-pyroglutamic acid, D-serine, L-serine, L-threonine, DL-carnitine, $\gamma$-aminobutyric acid, urocanic acid, inosine, uridine, thymidine, phenylethylamine, putrescine, 2-aminoethanol, 2,3butanediol, glycerol, DL- $\alpha$-glycerol phosphate, $\alpha$-D-glucose 1-phosphate or D-glucose 6-phosphate. The cell-wall peptidoglycan type is B2 $\beta$ with ornithine as the diagnostic diamino acid. The major menaquinone is MK-8; small amounts of MK-9 and MK-7 are also present. The polar lipid profile comprises phosphatidylglycerol, five unknown glycolipids, three unknown phospholipids and two unknown lipids. Mycolic acids are not present. The predominant cellular fatty acids are $\mathrm{C}_{18: 1}$, anteiso- $\mathrm{C}_{15: 0}$ and $\mathrm{C}_{14: 0}$ 2-OH. The DNA $\mathrm{G}+\mathrm{C}$ content of the type strain is $68.3 \mathrm{~mol} \%$.

The type strain, RS- $15^{\mathrm{T}}\left(=\right.$ KCTC $\left.13435^{\mathrm{T}}=\mathrm{DSM} 22180^{\mathrm{T}}\right)$, was isolated from rhizosphere soil of a plant (Peucedanum japonicum Thunb.) on Mara Island, Jeju, Republic of Korea.

\section{Acknowledgements}

This work was supported by the 21C Frontier Microbial Genomics and Application Center Program, Ministry of Science \& Technology, Republic of Korea. The author is thankful to Dr R Pukall for providing Frondihabitans australicus DSM $17894^{\mathrm{T}}$ and Seong Hae Seo for analysing amino acids in the cell-wall peptidoglycan.

\section{References}

De Ley, J., Cattoir, H. \& Reynaerts, A. (1970). The quantitative measurement of DNA hybridization from renaturation rates. Eur $J$ Biochem 12, 133-142.

Felsenstein, J. (1981). Evolutionary trees from DNA sequences: a maximum likelihood approach. J Mol Evol 17, 368-376.

Felsenstein, J. (1985). Confidence limits on phylogenies: an approach using the bootstrap. Evolution 39, 783-791.

Felsenstein, J. (1993). PHYLIP (phylogeny inference package), version 3.5c. Distributed by the author. Department of Genetics, University of Washington, Seattle, USA.

Fitch, W. M. (1971). Toward defining the course of evolution: minimum change for a specific tree topology. Syst Zool 20, 406-416.

Gordon, R. E., Barnett, D. A., Handerhan, J. E. \& Pang, C. H.-N. (1974). Nocardia coeliaca, Nocardia autotrophica, and the nocardin strain. Int J Syst Bacteriol 24, 54-63.

Greene, A. C., Euzéby, J. P., Tindall, B. J. \& Petal, B. K. C. (2009). Proposal of Frondihabitans gen. nov. to replace the illegitimate genus name Frondicola Zhang et al. 2007. Int J Syst Evol Microbiol 59, 447448.

Hancock, I. C. (1994). Analysis of cell wall constituents of Grampositive bacteria. In Chemical Methods in Prokaryotic Systematics, pp. 63-84. Edited by M. Goodfellow \& A. G. O’Donnell. Chichester: Wiley.

Huß, V. A. R., Festl, H. \& Schleifer, K. H. (1983). Studies on the spectrophotometric determination of DNA hybridization from renaturation rates. Syst Appl Microbiol 4, 184-192.

Jukes, T. H. \& Cantor, C. R. (1969). Evolution of protein molecules. In Mammalian Protein Metabolism, vol. 3, pp. 21-132. Edited by H. N. Munro. New York: Academic Press. 
Kroppenstedt, R. M. (1985). Fatty acid and menaquinone analysis of actinomycetes and related organisms. In Chemical Methods in Bacterial Systematics (Society for Applied Bacteriology Technical Series vol. 20), pp. 173-199. Edited by M. Goodfellow \& D. E. Minnikin. New York: Academic Press.

Lee, S. D. (2007). Labedella gwakjiensis gen. nov., sp. nov., a novel genus of the family Microbacteriaceae. Int J Syst Evol Microbiol 57, 2498-2502.

Lee, S. D. (2009). Amycolatopsis ultiminotia sp. nov., isolated from rhizosphere soil, and emended description of the genus Amycolatopsis. Int J Syst Evol Microbiol 59, 1401-1404.

Mesbah, M., Premachandran, U. \& Whitman, W. B. (1989). Precise measurement of the $\mathrm{G}+\mathrm{C}$ content of deoxyribonucleic acid by highperformance liquid chromatography. Int J Syst Bacteriol 39, 159-167.

Minnikin, D. E., Alshamaony, L. \& Goodfellow, M. (1975). Differentiation of Mycobacterium, Nocardia, and related taxa by thin layer chromatographic analysis of whole-cell methanolysates. J Gen Microbiol 88, 200-204.

Minnikin, D. E., Hutchinson, I. G., Caldicott, A. B. \& Goodfellow, M. (1980). Thin-layer chromatography of methanolysates of mycolic acid-containing bacteria. J Chromatogr A 188, 221-233.
Saitou, N. \& Nei, M. (1987). The neighbor-joining method: a new method for reconstructing phylogenetic trees. Mol Biol Evol 4, 406-425.

Schleifer, K. H. \& Kandler, O. (1972). Peptidoglycan types of bacterial cell walls and their taxonomic implications. Bacteriol Rev 36, 407-477.

Shirling, E. B. \& Gottlieb, D. (1966). Methods for characterization of Streptomyces species. Int J Syst Bacteriol 16, 313-340.

Thompson, J. D., Gibson, T. J., Plewniak, F., Jeanmougin, F. \& Higgins, D. G. (1997). The CLUSTAL_X windows interface: flexible strategies for multiple sequence alignment aided by quality analysis tools. Nucleic Acids Res 25, 4876-4882.

Uchida, K. \& Aida, K. (1984). An improved method for the glycolate test for simple identification of acyl type of bacterial cell walls. $J$ Gen Appl Microbiol 30, 131-134.

Wayne, L. G., Brenner, D. J., Colwell, R. R., Grimont, P. A. D., Kandler, O., Krichevsky, M. I., Moore, L. H., Moore, W. E. C., Murray, R. G. E. \& other authors (1987). International Committee on Systematic Bacteriology. Report of the ad hoc committee on reconciliation of approaches to bacterial systematics. Int J Syst Bacteriol 37, 463-464.

Zhang, L., Xu, Z. \& Patel, B. K. C. (2007). Frondicola australicus gen. nov., sp. nov., isolated from decaying leaf litter of a pine forest. Int $J$ Syst Evol Microbiol 57, 1177-1182. 